\title{
Differential Sulfation Remodelling of Heparan Sulfate by Extracellular 6-O-Sulfatases Regulates Fibroblast Growth Factor-Induced Boundary Formation by Glial Cells: Implications for Glial Cell Transplantation
}

\author{
Jennifer R. Higginson, ${ }^{1 \star}$ Sophie M. Thompson, ${ }^{2 \star}$ Alessandra Santos-Silva, ${ }^{1}$ Scott E. Guimond, ${ }^{2}$ Jeremy E. Turnbull, ${ }^{2 \dagger}$ \\ and Susan C. Barnett ${ }^{1 \dagger}$ \\ ${ }^{1}$ Institute of Infection, Immunity and Inflammation, College of Medical, Veterinary \& Life Sciences, Glasgow Biomedical Research Centre, Glasgow G12 \\ 8TA, United Kingdom, and ${ }^{2}$ Centre for Glycobiology, Institute of Integrative Biology, University of Liverpool, Liverpool L69 7XB, United Kingdom
}

Previously, it has been shown that rat Schwann cells (SCs), but not olfactory ensheathing cells (OECs), form a boundary with astrocytes, due to a SC-specific secreted factor. Here, we identify highly sulfated heparan sulfates (HSs) and fibroblast growth factors (FGFs) 1 and 9 as possible determinants of boundary formation induced by rat SCs. Disaccharide analysis of HS in SC-conditioned and rat OECconditioned media showed that SCs secrete more highly sulfated HS than OECs. The dependence of the boundary-forming activity on high levels of sulfation was confirmed using a panel of semisynthetic modified heparins with variable levels of sulfation. Furthermore, extracellular HS 6-O-endosulfatase enzymes, Sulf 1 and Sulf 2, were expressed at a significantly lower level by SCs compared with OECs, and siRNA reduction of Sulfs in OECs was, in itself, sufficient to induce boundary formation. This demonstrates a key role for remodelling (reduction) of HS 6-O-sulfation by OECs, compared with SCs, to suppress boundary formation. Furthermore, specific anti-FGF1 and anti-FGF9 antibodies disrupted SC-astrocyte boundary formation, supporting a role for an HS sulfation-dependent FGF signaling mechanism via FGF receptors on astrocytes. We propose a model in which FGF1 and FGF9 signaling is differentially modulated by patterns of glial cell HS sulfation, dependent on Sulf 1 and Sulf 2 expression, to control FGF receptor 3-IIIb-mediated astrocytic responses. Moreover, these data suggest manipulation of HS sulfation after CNS injury as a potential novel approach for therapeutic intervention in CNS repair.

\section{Introduction}

The adult mammalian CNS has limited capacity for repair. Spinal cord injury usually results in formation of a glial scar and permanent loss of sensory, motor, and autonomic function. A potential repair strategy is cell transplantation, for which glial cells or stem cells are popular candidates. Many researchers focus on glial cells, such as Schwann cells (SCs) from the peripheral nervous system, or olfactory ensheathing cells (OECs) from the olfactory system, as they inherently support axon regeneration (Franklin and Barnett, 2000; Raisman, 2001; Barnett and Riddell, 2007). We have shown previously that OECs and SCs have some important dif-

Received Dec. 20, 2011; revised July 12, 2012; accepted July 17, 2012.

Author contributions: S.M.T., A.S.S., S.E.G., J.E.T., and S.C.B. designed research; J.R.H. and S.M.T. performed research; J.R.H., S.M.T., and S.E.G. analyzed data; J.R.H., S.M.T., S.E.G., J.E.T., and S.C.B. wrote the paper.

J.R.H. and S.M.T. were funded by a grant from The Wellcome Trust to J.E.T., S.C.B., and S.E.G.

The authors declare no competing financial interests.

*J.R.H. and S.M.T. contributed equally to this work.

†J.E.T. and S.C.B. contributed equally as senior authors.

Correspondence should be addressed to either of the following: Professor Susan C. Barnett, Institute of Infection, Immunity and Inflammation, Biomedical Research Centre, 120 University Place, Glasgow G12 8TA, UK, E-mail: Susan.Barnett@glasgow.ac.uk; or Professor Jeremy Turnbull, Centre for Glycobiology, Institute of Integrative Biology, University of Liverpool, Crown St., Liverpool L69 7XB, UK, E-mail: j.turnbull@liverpool.ac.uk.

DOI:10.1523/JNEUROSCI.6340-11.2012

Copyright $\odot 2012$ the authors $\quad 0270-6474 / 12 / 3015902-11 \$ 15.00 / 0$ ferences that might influence their selection for transplantation. These differences, which have been detected not only in vitro (Lakatos et al., 2000; Fairless and Barnett, 2005), but also after transplantation in vivo, make it possible for OECs, compared to SCs, to better integrate with host astrocytes (Lakatos et al., 2003; Santos-Silva et al., 2007). This present work aims to determine which differences in the cell biology of OECs and SCs confer advantages for transplantation and may direct future efforts to improve transplantation of SCs.

It has been shown that OECs and SCs share many biological characteristics, including antigenic and morphological phenotypes and the ability to myelinate axons with peripheral-type myelin (Franklin and Barnett, 2000; Chuah and West, 2002; Barnett and Riddell, 2007; Franssen et al., 2007). However, they interact differently with astrocytes, the main component of the glial scar (Fawcett and Asher, 1999), in that SCs induce a reactive astrocyte phenotype through which axons cannot regenerate (Silver and Miller, 2004; Pekny and Nilsson, 2005), whereas OECs do not (Lakatos et al., 2000; Fairless and Barnett, 2005; Santos-Silva et al., 2007). This characteristic is in line with the native behavior of OECs in the olfactory system, where they intermix with astrocytes (Raisman, 1985; Li et al., 2005). Our previous studies demonstrated that SCs and astrocytes form a boundary on contact and 
A

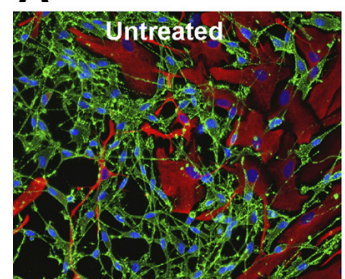

B

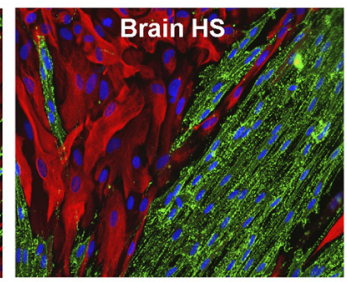

C

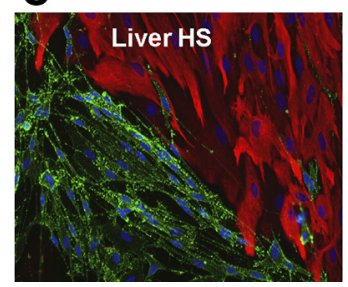

D

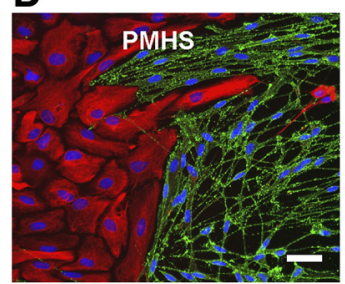

E

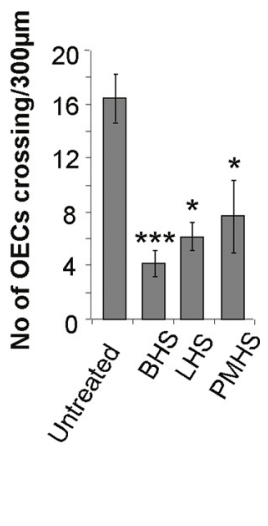

Figure 1. HS from a variety of tissue sources can induce a boundary in $0 \mathrm{EC}$-astrocyte confrontation assays. A-D, $30 \mu \mathrm{g} / \mathrm{ml} \mathrm{HS}$ purified from brain (BHS, $\boldsymbol{B}$ ), liver (LHS, $\boldsymbol{C}$ ), and porcine intestinal mucosa (PMHS, $\boldsymbol{D}$ ), were added to confrontation assays of $0 \mathrm{ECS}$ and astrocytes and compared with an untreated control $(\boldsymbol{A})$. After $2 \mathrm{~d}$ of treatment, cells were fixed and stained for GFAP (red) and p75 ${ }^{\text {NTR }}$ (green). $\boldsymbol{E}$, The numbers of OECs mingling with astrocytes across a $300 \mu \mathrm{m}$ line were counted. HS from all three tissue sources prevented $0 E C$ from crossing into the astrocyte monolayer, resulting in the formation of a boundary. Error bars indicate \pm SEM. Scale bar, $50 \mu \mathrm{m} .{ }^{*} p<0.05,{ }^{* * *} p<0.001$ versus control.

occupy distinct, nonoverlapping areas (Lakatos et al., 2000). In contrast, OECs and astrocytes freely intermingle, without inducing a reactive astrocyte phenotype, although the addition of SCconditioned medium (SCM) or heparin can induce SC-like behavior in OECs. Furthermore, SCs will mingle with astrocytes if treated with an fibroblast growth factor (FGF) receptor inhibitor, suggesting an involvement of heparan sulfate (HS)dependent FGF signaling (Santos-Silva et al., 2007).

HS proteoglycans are cell surface and matrix molecules, each composed of a core protein to which one or more HS polysaccharide chains are attached. These chains consist of repeating disaccharide units of $N$-acetylglucosamine and glucuronic acid that are modified enzymatically by $\mathrm{N}$-deacetylation/ $\mathrm{N}$-sulfation, 2-Osulfation, 6-O-sulfation, 3-O-sulfation, and epimerization of glucuronic acid to iduronic acid, to generate functionally specific saccharide sequences (Ori et al., 2008). Furthermore, HS chains are also remodelled extracellularly by 6-O-endosulfatase enzymes (Sulfs), which selectively remove 6-O-sulfates to introduce a further level of structural sophistication (Dhoot et al., 2001; MorimotoTomita et al., 2002; Ai et al., 2006). The specific HS sequences synthesized modulate the cellular functions of a diverse array of protein ligands, including FGFs (Turnbull et al., 1992; Guimond et al., 1993; Maccarana et al., 1993; Brickman et al., 1998; Guimond and Turnbull, 1999; Kreuger et al., 2001; Ford-Perriss et al., 2002; Ashikari-Hada et al., 2004). Here, we demonstrate that OECs and SCs have distinct HS molecular phenotypes and implicate highly sulfated HS produced by SCs in the formation of a gliotic scar. We provide evidence that sulfation levels are differentially remodelled by OECs and SCs via Sulf 1 and Sulf 2, and identify FGF1 and FGF9 as possible growth factors involved in the induction process. We propose a model in which specific FGFs act in concert with regulated patterns of glial HS sulfation to control astrocytic responses.

\section{Materials and Methods}

Generation of purified glial cells

All primary neural cultures were generated from Sprague Dawley rat pups of either sex. As described previously (Noble and Murray, 1984; Lakatos et al., 2000), purified type 1 astrocytes were prepared by digesting cortices [dissected from 1-d-old Sprague Dawley (SD) rats] in $1.33 \%$ $(\mathrm{w} / \mathrm{v})$ collagenase (Sigma-Aldrich), seeding $\left(\sim 2 \times 10^{7}\right.$ cells per $75 \mathrm{~cm}^{2}$ flask $)$ and culturing the cells in poly-L-lysine (PLL, $13.3 \mu \mathrm{g} / \mathrm{ml}$, Sigma-Aldrich)-coated $75 \mathrm{~cm}^{2}$ flasks for $10-12$ d. The cells were maintained in DMEM (Invitrogen) supplemented with $10 \%(\mathrm{v} / \mathrm{v})$ fetal bovine serum (FBS) (Sigma-Aldrich) and L-glutamine (2 mM, Sigma-Aldrich) (DMEM-FBS). Confluent flasks were shaken on a rotary platform overnight at $37^{\circ} \mathrm{C}$ to remove contaminating oligodendrocyte precursor cells. The remaining cells were 8595\% type 1 astrocytes as identified by labeling for glial fibrillary acidic protein (GFAP), an astrocyte cell-specific marker.

OECs were isolated from the olfactory bulb of 7-d-old SD rat pups and purified using magnetic nanoparticles (Stemcell Technologies) prebound with the $\mathrm{p} 75^{\mathrm{NTR}}$ antibody (mouse IgG1, Abcam) (Higginson and Barnett, 2011). The cells were grown in low-glucose DMEM with $5 \%(\mathrm{v} / \mathrm{v})$ FBS and $2 \mathrm{~mm}$ L-glutamine and further supplemented with DMEMBottenstein and Sato (DMEM-BS) (Bottenstein et al., 1979), FGF2 (25 ng/ml, Peprotech), heregulin $\beta-1$ ( $50 \mathrm{ng} / \mathrm{ml}$, R\&D Systems), forskolin $\left(5 \times 10^{-7} \mathrm{M}\right.$, Sigma-Aldrich), and astrocyte-conditioned media (ACM) (1:5, fresh serum-free media taken after incubation with a confluent astrocyte monolayer for $48 \mathrm{~h}$ ) (Noble and Murray, 1984; Alexander et al., 2002).

SCs were purified using a modification of the method described by Brockes et al. (1979). This modification involved treating the cultures with cytosine arabinoside $\left(10^{-5} \mathrm{M}\right.$, Sigma-Aldrich), followed by incubation with anti-Thy1.1 antibody (1:1 supernatant, Sigma-Aldrich) and rabbit complement (1:6, Harlan Laboratories) to reduce contamination by fibroblasts (Lakatos et al., 2000). All cell cultures were grown in PLLcoated tissue culture flasks.

Collection of SC-conditioned medium, OEC-conditioned medium, and ACM

Confluent cultures of purified SCs or OECs in $75 \mathrm{~cm}^{2}$ flasks (maintained in vitro for 2-6 weeks) were rinsed twice with $\mathrm{PBS}, \mathrm{pH} 7.4$, and $7 \mathrm{ml}$ of DMEM-BS without growth factors added. Cultures were maintained for a further $2 \mathrm{~d}$ before medium collection. Collected medium was centrifuged to remove cellular debris and filtered through a $0.2 \mu \mathrm{m}$ filter (Millipore). The same procedure was used for generating ACM, except that confluent astrocyte cultures were maintained in $11 \mathrm{ml}$ of DMEM-BS. Conditioned media was added to cell cultures at a 1:1 ratio with DMEMFBS.

\section{Confrontation assays}

Confrontation assays were performed as described by Wilby et al. (1999) and Lakatos et al. (2000) with some modifications. Briefly, $70 \mu$ l containing 10,000 OECs or SCs were seeded into one well of a silicon Ibidi culture insert on a PLL-coated glass coverslip (Ibidi). Into the opposing, parallel well, 10,000 astrocytes were seeded. Cells were allowed to attach for $1 \mathrm{~h}$ before careful removal of the insert followed by a wash with DMEM-FBS to remove unattached cells. Cultures were maintained in DMEM-FBS and allowed to grow toward each other over a period of 5-7 d, allowing time for cells to make contact and interact (Lakatos et al., 2000). In some experiments, tissue HS, modified heparins, blocking antibodies, or conditioned medium were added to the cultures after the cells had contacted each other. Cultures were then immunolabeled using anti-GFAP for astrocytes [1:500; anti-rabbit (Dako)] and anti-p75 NTR for OECs and SCs [1:1; IgG1; hybridoma supernatant (Yan and Johnson, 1988)]. Fluorescent images were captured using an Olympus BX51 fluorescent microscope and Image-Pro software. Using Adobe Photoshop Elements 7.0, a $300 \mu \mathrm{m}$ line was drawn along the interface between astrocytes and either OECs or SCs. The numbers of OECs or SCs crossing 

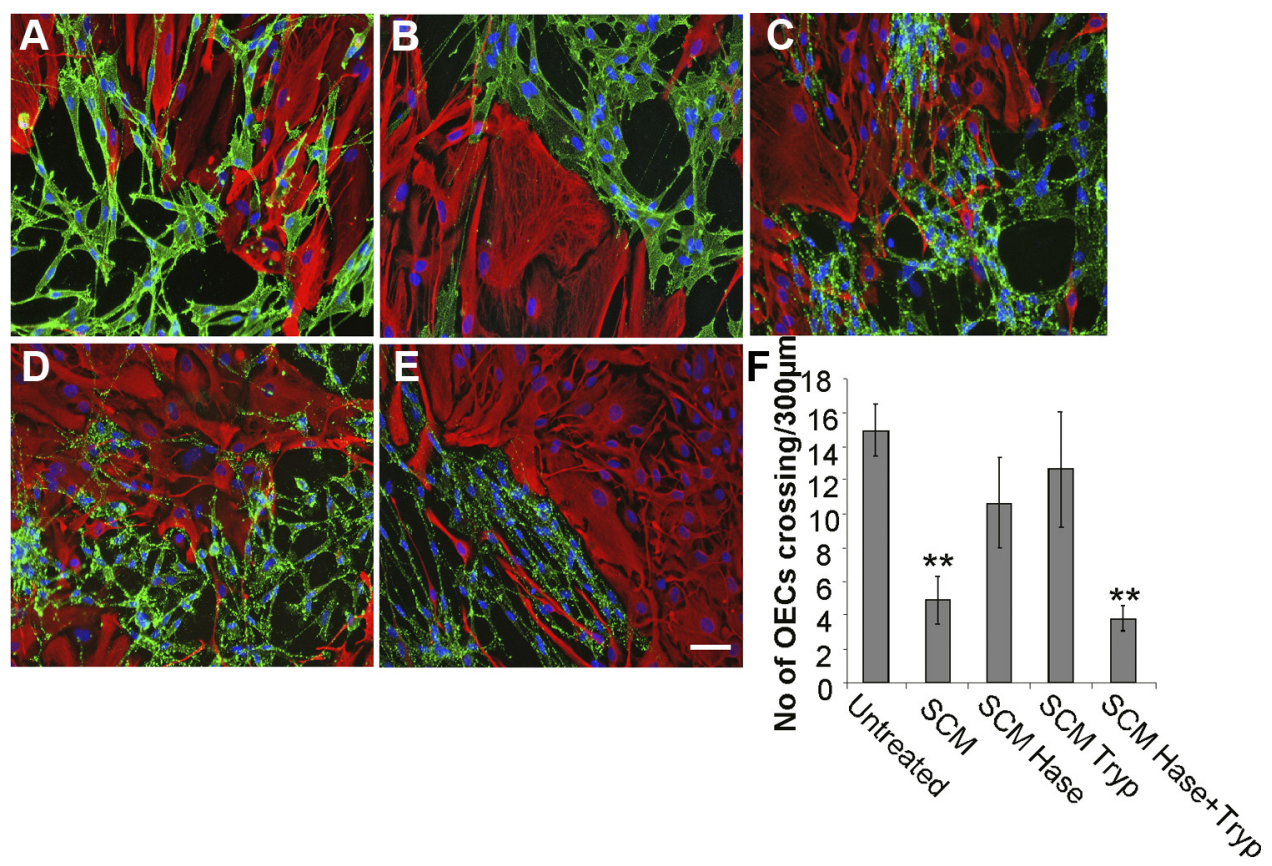

Figure 2. Both $\mathrm{HS}$ and protein components of $S C M$ are required for boundary formation. $A-E$, Confrontation assays of $0 E C S$ and astrocytes were performed in the presence of normal medium/untreated $(\boldsymbol{A})$; SCM (B); heparinase-treated SCM (C); trypsin-treated SCM (D); and 1:1 combination of heparinase-treated and trypsin-treated SCM (E). After $2 \mathrm{~d}$ of treatment, cells were fixed and stained for GFAP (red) and p75 NTR (green). $\boldsymbol{F}$, The number of cells mingling with astrocytes was counted across a $300 \mu \mathrm{m}$ line. Heparinase-treated (Hase) or trypsin-treated (Tryp) SCM did not induce boundary formation when added to assays individually. However, when combined, a boundary formed, suggesting that both an $\mathrm{HS}$ and a protein component are required for activity. Error bars indicate \pm SEM. Scale bar, $50 \mu \mathrm{m} .{ }^{* *} p<0.01$ versus control.

the cell-cell boundary were counted and averaged over five randomly chosen fields. Experiments were repeated at least three times.

\section{Treatments}

Modified heparins. Modified heparins (a gift from Dr. E.A. Yates, University of Liverpool, UK) were produced semisynthetically by chemical modification (selective desulfation) of heparin. These structurally distinct, model "HS-mimetic" polysaccharides (Yates et al., 1996) are useful tools for investigating structure-activity relationships of HS (Irie et al., 2002; Yates et al., 2004; Guimond et al., 2006; Patey et al., 2006). The disaccharide structures of the heparins are indicated in Figure 3. Heparins were added to confrontation assays at $10 \mu \mathrm{g} / \mathrm{ml}$ at the stage when cells made contact (day 0 ) and treatment was repeated on day 2. Cultures were fixed and stained as described above on day 3.

HS from various tissue sources. Porcine mucosal HS was a gift from Organon. Porcine liver and rat brain HS were purified using previously described methods (Lyon and Gallagher, 1991; Esko, 2001). Confrontation assays were treated with polysaccharides for $2 \mathrm{~d}$ (day 0 and day 2$)$ at a final concentration of $30 \mu \mathrm{g} / \mathrm{ml}$.

Heparinase and trypsin treatment of conditioned medium. Proteins in SCM were digested by the addition of trypsin at a final ratio of 1:50 trypsin/protein and incubated for $12 \mathrm{~h}$ at $37^{\circ} \mathrm{C}$ (amount of protein was estimated by measuring the UV absorbance at $280 \mathrm{~nm}$ ). Trypsin was inactivated by addition of soybean trypsin inhibitor (1:10 of final trypsin concentration). HS was digested by the addition of $10 \mathrm{mU}$ each of heparinase I [Enzyme Commission (EC) 4.2.2.7], II (EC number not assigned), and III (EC 4.2.2.8) (Ibex Technologies) to $4 \mathrm{ml}$ of SCM, followed by incubation at $37^{\circ} \mathrm{C}$ for $6 \mathrm{~h}$. A further $10 \mathrm{mU}$ of each heparinase enzyme was added to SCM and the reaction incubated overnight at $37^{\circ} \mathrm{C}$. Treatment of confrontation assays was performed by replacing half of the media with untreated SCM, heparinase-treated SCM, trypsintreated SCM, or 50:50 heparinase/trypsin-treated SCM. Confrontation assays were treated for $2 \mathrm{~d}$.

FGF inhibition. Anti-FGF2 (Clone bFM-1) (Millipore), anti-FGF9 (Clone 36912), and anti-FGF1 (both R\&D Systems) neutralizing antibodies were added to confrontation assays at a final concentration of 1 $\mu \mathrm{g} / \mathrm{ml}$, at the stage when cells made contact. Treatment was repeated for $2 \mathrm{~d}$ and then cultures were fixed and stained as described above on day 3 .

\section{HPLC analysis of HS disaccharides in SCM and}

\section{OEC-conditioned medium}

SCM and OEC-conditioned medium (OCM) were collected from 75 $\mathrm{cm}^{2}$ flasks of confluent OECs or SCs, frozen and stored at $-20^{\circ} \mathrm{C}$ until enough material was collected for detection ( $180 \mathrm{ml}$ of OCM and $90 \mathrm{ml}$ of SCM). OCM and SCM were rotated with $0.1 \mathrm{ml}$ of DEAE-sephacel (Sigma-Aldrich) per $10 \mathrm{ml}$, overnight at $4^{\circ} \mathrm{C}$, and then centrifuged at $3382 \times g$ for $5 \mathrm{~min}$ and unbound material in the supernatant removed. DEAE beads were washed three times with 10 column volumes of PBS, and then washed twice with 10 column volumes of $0.25 \mathrm{M} \mathrm{NaCl}$ in PBS. Bound material containing HS proteoglycans (HSPGs) was eluted with 10 column volumes of $2 \mathrm{M} \mathrm{NaCl}$ in PBS and desalted over two, in-line 5 $\mathrm{ml}$ HiTrap desalting columns (GE Healthcare UK) using an AKTA FPLC system. Desalted material was then freeze-dried.

\section{Heparinase digestion}

Lyophilized material was resuspended in heparinase buffer (100 mM sodium acetate, $0.1 \mathrm{~mm}$ calcium acetate, $\mathrm{pH}$ 7) and $2.5 \mathrm{mU}$ each of heparinase I, II, and III were added and incubated for $3 \mathrm{~h}$ at $37^{\circ} \mathrm{C}$. After this time, a further $2.5 \mathrm{mU}$ of heparinase I, II, and III were added and the reaction incubated overnight at $37^{\circ} \mathrm{C}$. Another $2.5 \mathrm{mU}$ of heparinase I, II, and III were then added and incubated for a further $3 \mathrm{~h}$. As a control, 100 $\mu \mathrm{g}$ of heparin was digested in the same way. Digested samples were then incubated at $95^{\circ} \mathrm{C}$ for $5 \mathrm{~min}$ to stop the reaction and taken up in $800 \mu \mathrm{l}$ of HPLC-grade water.

\section{C18 HPLC}

HS disaccharides were separated from samples using a Discovery C18 HPLC column (Supelco, Sigma-Aldrich) $(25 \mathrm{~cm} \times 4.6 \mathrm{~mm}, 5 \mu \mathrm{m})$ on a Shimadzu SPD 10A HPLC system. Buffer A was HPLC-grade water and Buffer B was $80 \%$ (v/v) methanol. Elution profiles were monitored by UV absorbance at $232 \mathrm{~nm}$. Samples were injected in buffer A and the void volume containing HS disaccharides was collected and freeze-dried for 

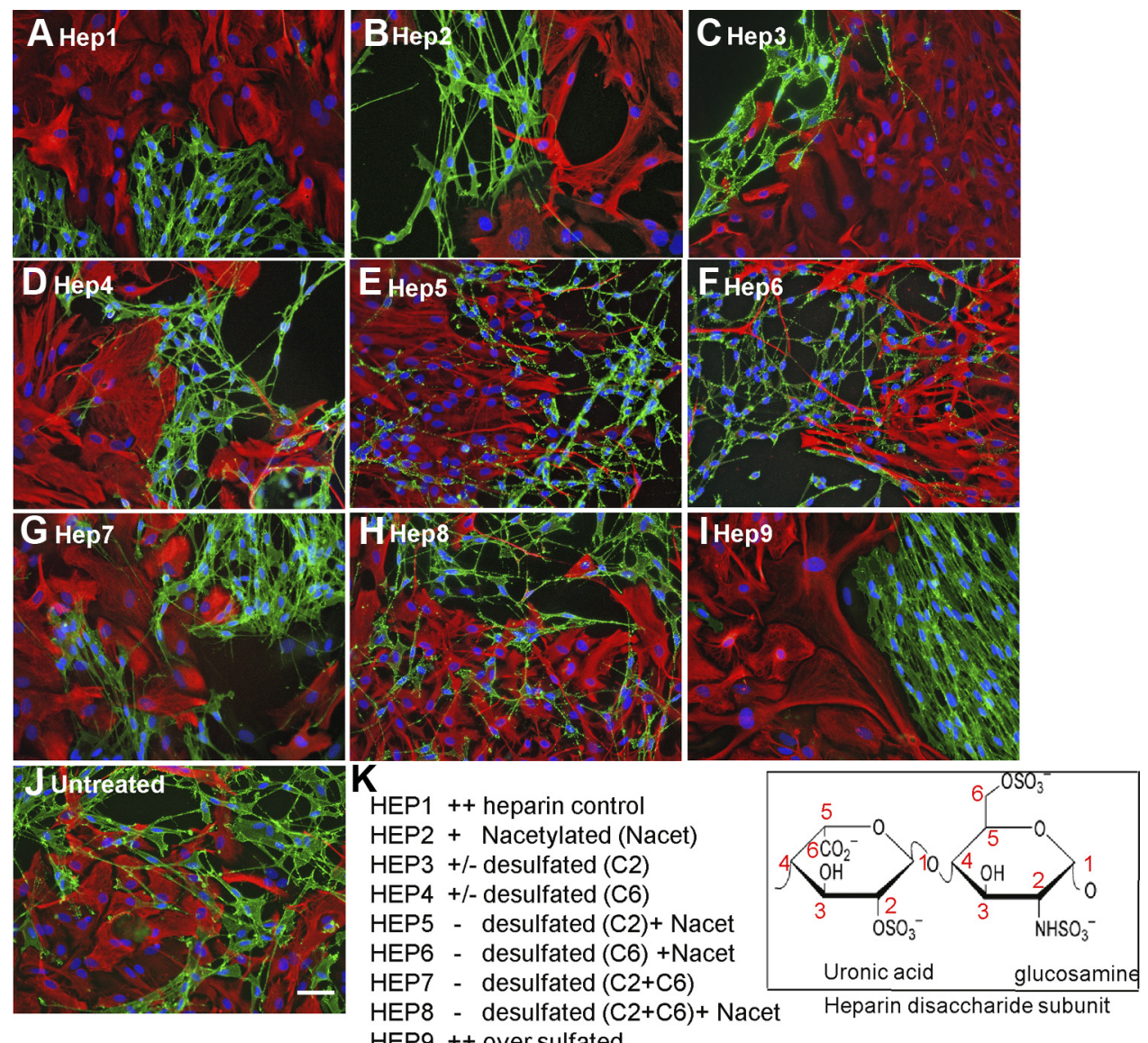

Figure 3. HS sulfation is critical for boundary formation. $A-J$, Confrontation assays of $0 E C$ s and astrocytes were performed in the presence of $10 \mu \mathrm{g} / \mathrm{ml}$ of modified heparins. The disaccharide structures of the heparins are indicated. After $2 \mathrm{~d}$ of treatment, cells were fixed and stained for GFAP (red) and p $75^{\mathrm{NTR}}$ (green). $\boldsymbol{K}$, Assays were scored using a graded scoring system to assess the ability of each modified heparin to promote boundary formation [i.e., mingling $(-)$, partial boundary $(+/-)$, or complete boundary $(++)$ ]. Control heparin effect was scored as ++ . Modified heparins with the highest levels of sulfation (Hep1, Hep2, Hep3, Hep4, and Hep9) induced boundaries between OECs and astrocytes, whereas those with lower levels of sulfation (Hep5, Hep6, Hep7, and Hep8) did not. The images are representative of at least three independent experiments. Scale bar, $50 \mu \mathrm{m}$.

BODIPY labeling. Bound material (containing hydrophobic material, including HSPG core proteins) was eluted using a linear gradient of $0-50 \%$ buffer $\mathrm{B}>30 \mathrm{~min}$ at a flow rate of $1 \mathrm{ml} / \mathrm{min}^{-1}$.

\section{BODIPY labeling of HS disaccharides}

Freeze-dried HS disaccharides were labeled with BODIPY FL hydrazide (5 mg/ml; 4,4-difluoro-5, 7-dimethyl-4-bora-3a, 4a-diaza-s-indacene-3propionic acid hydrazide; Invitrogen) as previously described (Skidmore et al., 2006, 2009, 2010). Digested heparin control and HS disaccharide standards (Iduron) were labeled in the same way. Labeled samples were applied to silica gel thin-layer chromatography (TLC) aluminum plates and free BODIPY tag separated from labeled disaccharides with butanol. Labeled HS disaccharides were removed from the TLC plates and solubilized in $800 \mu \mathrm{l}$ of HPLC-grade water.

\section{Strong anion exchange HPLC}

Strong anion exchange (SAX) separations were performed on a Propac PA1 column $(25 \mathrm{~cm} \times 9 \mathrm{~mm}, 5 \mu \mathrm{m})$ using a Shimadzu SPD 10A HPLC system. Elution profiles were monitored by UV absorbance at $232 \mathrm{~nm}$ and fluorescent detection using a Shimadzu RF10AXL spectrofluorometer. Buffer A was $150 \mathrm{~mm} \mathrm{NaOH}$ and Buffer B was $150 \mathrm{~mm} \mathrm{NaOH}, 2 \mathrm{M}$ $\mathrm{NaCl}$. Elution profiles were monitored by UV absorbance at $232 \mathrm{~nm}$ and fluorescent detection at $\lambda_{\mathrm{ex}}=488 \mathrm{~nm}, \lambda_{\mathrm{em}}=520 \mathrm{~nm}$. Samples were injected and the flow held at $2 \mathrm{ml} / \mathrm{min}^{-1}$ in buffer A until all remaining free tag had been eluted. Fluorescently labeled disaccharides were then eluted using a linear gradient of $0-50 \%$ buffer B for $>45 \mathrm{~min}$ at $2 \mathrm{ml} /$ $\min ^{-1}$. The column was then washed with a 10 min elution in $300 \mathrm{~mm}$ $\mathrm{NaOH}, 2 \mathrm{M} \mathrm{NaCl}$, before returning to $150 \mathrm{~mm} \mathrm{NaOH}$.

\section{Quantitative real-time PCR}

RNA from monocultures of OECs and SCs was extracted using a Qiagen RNeasy Mini Kit (Qiagen) following manufacturer's instructions. RNA quality and integrity were checked using the Nanodrop 1000 (Thermo Fisher Scientific). Following RNA extraction, cDNA was synthesized from $1 \mu \mathrm{g}$ of RNA using the QuantiTect Reverse Transcription kit (Qiagen). Real-time PCR was performed with $100 \mathrm{ng}$ of cDNA in a $20 \mu \mathrm{l}$ reaction volume using QuantiTect primer assays and the Quantifast SYBR-green PCR kit (Qiagen). Experiments were performed in triplicate for each sample in 96-well plates using the Applied Biosystems 7500 real-time PCR system. PCR cycle settings were $95^{\circ} \mathrm{C}$ for $5 \mathrm{~min}$, followed by 40 cycles of $95^{\circ} \mathrm{C}$ for $10 \mathrm{~s}$, then $60^{\circ} \mathrm{C}$ for $30 \mathrm{~s}$. Cycle threshold was calculated based on GAPDH (endogenous control), which was confirmed to be comparable in both cell types. Expression of all genes were expressed relative to GAPDH in each sample, derived using the comparative delta-delta threshold change method (relative quantification). Three independent cell preparations were analyzed.

\section{siRNA transfections}

Purified OECs were seeded at a density of 5000 cells/100 $\mu$ l into one chamber of an Ibidi culture insert (Ibidi) sealed onto a PLL-coated coverslip in a well of a 24-well plate. Cells were cultured in defined OEC medium for $24 \mathrm{~h}$, after which the medium was replaced with low-serum [2\% (v/v) FBS] OEC medium containing $1 \mu \mathrm{M}$ siRNA. siRNA sequences were obtained from Dharmacon/Thermo Scientific (Sulf 1, E-09374600-0005; Sulf 2, E-093673-00-0005; nontargeting, D-001910-01-05; Thermo Fisher Scientific). Sulf 1 and Sulf 2 siRNAs were added in com- 

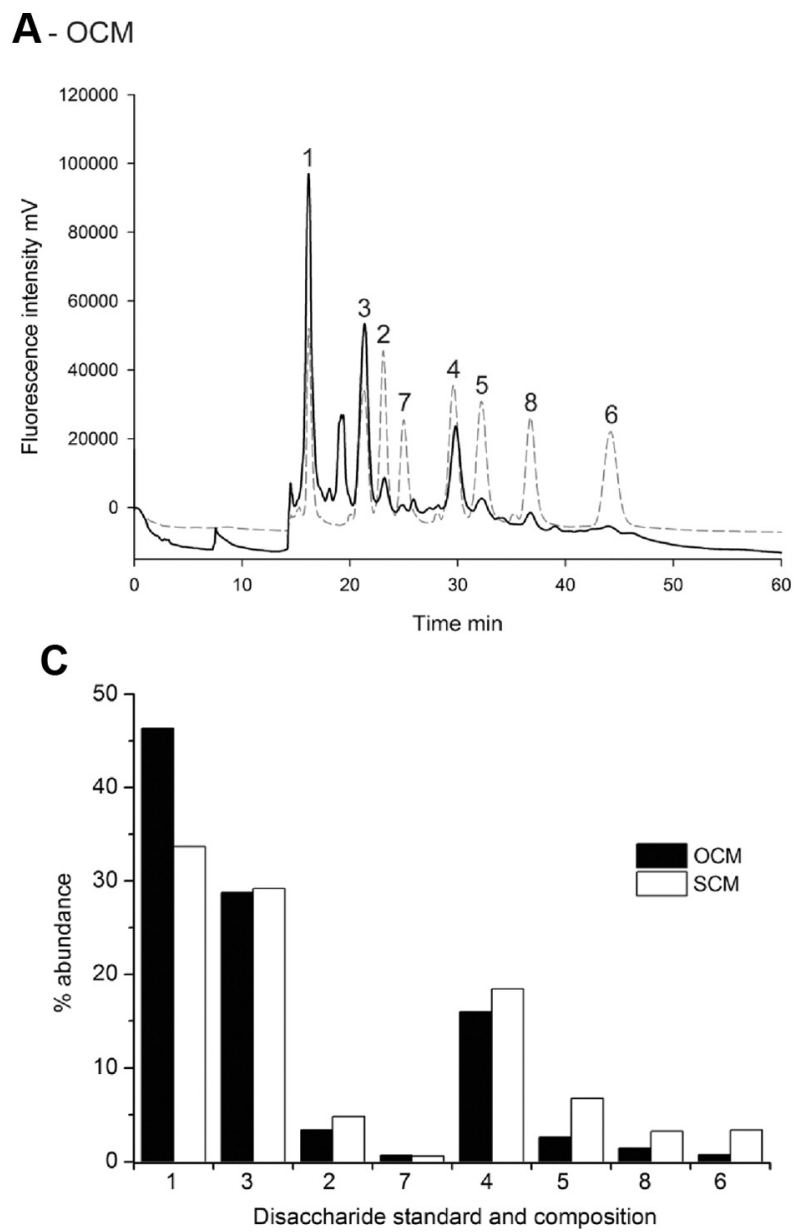

B - SCM

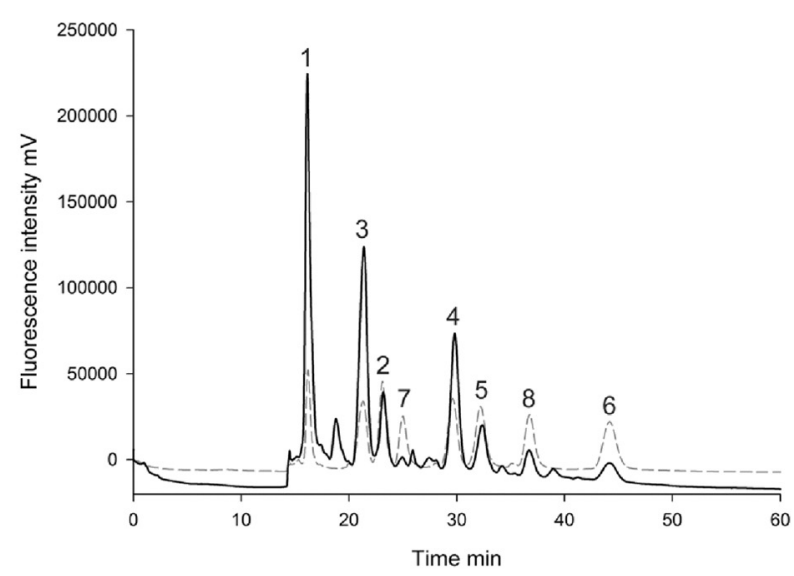

D

\begin{tabular}{|c|c|c|c|c|c|}
\hline & \multicolumn{4}{|c|}{$\%$ of HS modified with: } & \multirow[b]{2}{*}{$\begin{array}{c}\text { Average sulfates per } \\
\text { disaccharide }\end{array}$} \\
\hline & NAC & NS & $6 \mathrm{~S}$ & $2 S$ & \\
\hline OCM & 51.9 & 48.1 & 21.6 & 5.5 & 0.75 \\
\hline SCM & 42.3 & 57.7 & 29.8 & 13.9 & 1.02 \\
\hline
\end{tabular}

Disaccharide Standards - in order of elution

1. UA-GIcNAc, 3. UA-GIcNS, 2. UA-GIcNAc(6OS), 7. UA(2OS)-GIcNAc,

4. UA -GlcNS(6OS), 5. UA(2OS)-GIcNS, 8. UA(2OS)-GlcNAc(6OS),

6. UA(2OS)-GICNS(6OS)

Figure 4. SAX HPLC analysis of fluorescently labeled HS disaccharides purified from OCM and SCM indicate that SCS and OECS secrete distinct HS structures. $\boldsymbol{A}, \boldsymbol{B}, \mathrm{HS}$ purified from OCM $(\boldsymbol{A})$ and SCM (B) was digested with heparinase enzymes to generate HS disaccharides, which were fluorescently labeled with BODIPY and separated by SAX HPLC over a 45 min, 0 - 1.5 M NaCl gradient (black lines). HS disaccharide standards were separated over the same gradient as a reference guide (dashed lines). C, Relative abundances of the eight HS standard disaccharides in each conditioned medium sample were calculated as a percentage of total HS. D, Summary table detailing the composition of OCM HS and SCM HS. SCM HS was found to be more highly sulfated than OCM HS, with an average of 1.02 sulfates per disaccharide compared with 0.75 sulfates per disaccharide in OCM HS. SCM HS contained a higher proportion of disulfated and trisulfated disaccharides (disaccharides 4, 5 , 8 , and 6) and the singly 6-0-sulfated disaccharide (disaccharide 2) compared with OCM HS (C), which contained a higher proportion of the unsulfated disaccharide (disaccharide 1) (C, D). UA, uronic acid; GlcN, glucosamine; NAc, N-acetyl; NS, N-sulfate; 60S, 6-0-sulfate; 20S, 2-0-sulfate.

bination. After $72 \mathrm{~h}$, astrocytes were seeded into the opposing chamber of the culture insert and confrontation assays performed as previously described. The extent of gene knockdown was assessed by qPCR using RNA purified from siRNA-treated cells and from Sulf 1-specific and Sulf 2-specific primers.

\section{Results}

The induction of astrocyte hypertrophy by SCs and the resulting formation of a cellular boundary remains a barrier to their use in cell transplantation therapies for the repair of spinal cord injury. Previous work has shown that SC-induced boundary formation involves HS and FGF receptors because digestion of HS or chemical blockage of FGF receptors inhibits boundary formation and promotes cell mingling (Santos-Silva et al., 2007). Improved knowledge of the biological factors and signaling pathways underlying SC-induced boundary formation will aid the development of strategies to facilitate injury repair by improving the incorporation of transplanted SCs into host CNS tissue and prevent activation of an astrocytic stress response by invading host SCs. Using a combination of cellular, biochemical, and genetic approaches, we, therefore, investigated the role of HS and FGF signaling in the distinct interactions of SCs and OECs with astrocytes.
HS from different sources induces OEC-astrocyte boundaries Heparin has been shown to induce a boundary between OECs and astrocytes (Santos-Silva et al., 2007). To determine whether this activating effect of heparin on boundary formation could be induced by more physiologically relevant HS species, confrontation assays of OECs and astrocytes were treated with HS purified from different tissues. While OECs and astrocytes mingled freely in control assays (Fig. 1A), strong boundaries were formed upon addition of HS purified from rat brain (Fig. $1 B$ ), rat liver (Fig. $1 C$ ), or porcine intestinal mucosa (Fig. $1 D$ ). Quantification of the extent of boundary formation, assessed by the number of OECs crossing into the astrocyte monolayer, showed that HS from all three sources had similar activity (Fig. 1E).

\section{Induction of an OEC-astrocyte boundary by SCM requires both a protein and an HS component}

Initially, the relative requirements for protein and HS components in SCM for boundary formation were investigated. The active role of SCM HS in the induction of an OEC-astrocyte boundary was confirmed, since heparinase treatment of SCM negates the boundary-forming effect (Fig. 2C). SCM treated separately with either heparinase or trypsin did not induce boundary 


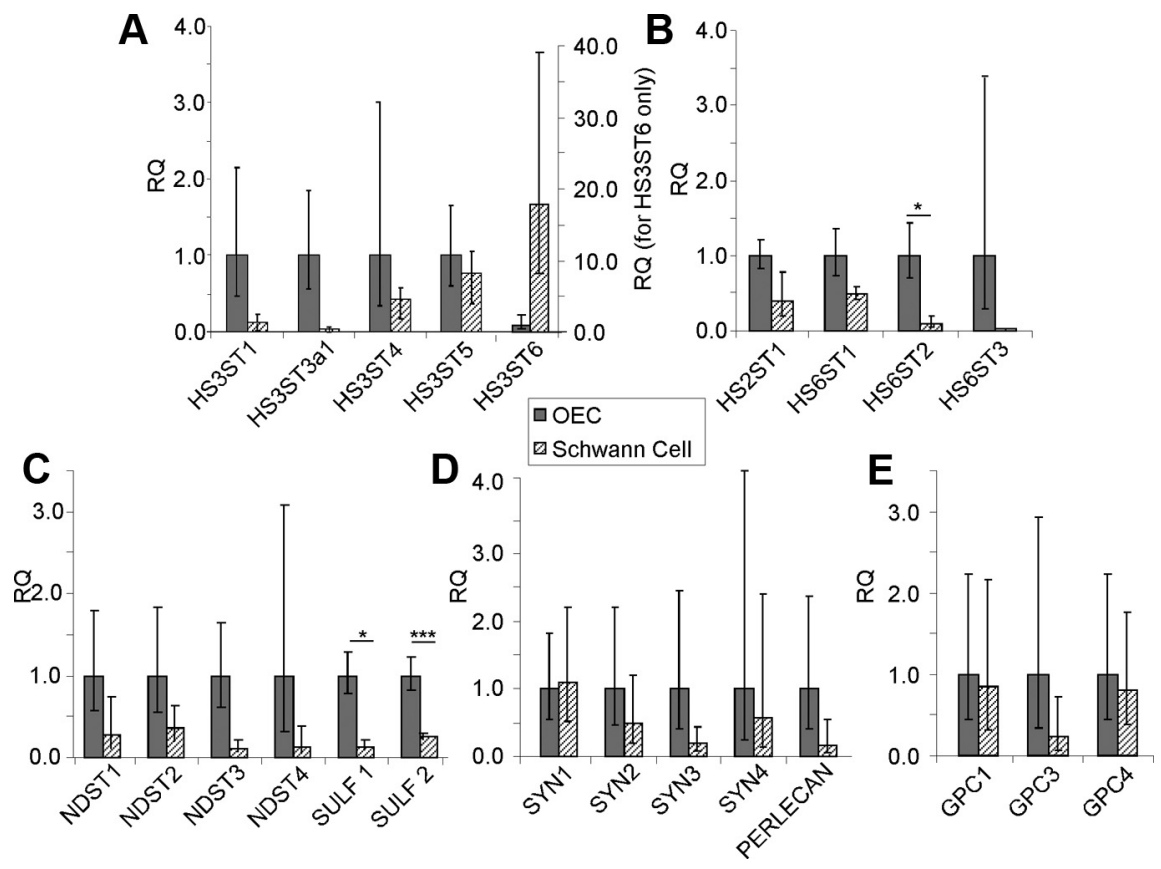

Figure 5. Expression profile of HS biosynthetic enzymes and HSPGs in OECS and SCs. Using qRT-PCR, the expression of HS biosynthetic enzymes and HSPG core proteins by $0 \mathrm{EC}$ s and SCS were compared. $\boldsymbol{A}-\boldsymbol{E}$, Data are represented as relative quantification (RQ) of HS biosynthetic enzymes ( $\boldsymbol{A}-\boldsymbol{C})$ and HSPGs (D-E) in SCs, normalized to the expression in OECs. HS6ST2, Sulf 1 , and Sulf 2 were more highly expressed by 0ECS. HS3ST6 was expressed uniquely by SCS, whereas HS6ST3 and HS3ST3a1 were expressed uniquely by $0 \mathrm{ECS}$. HS3ST2, GPC2, and GPC5 were not expressed by either cell type. Error bars indicate \pm SEM. ${ }^{*} p<0.05,{ }^{* * *} p<$ 0.001 versus control.
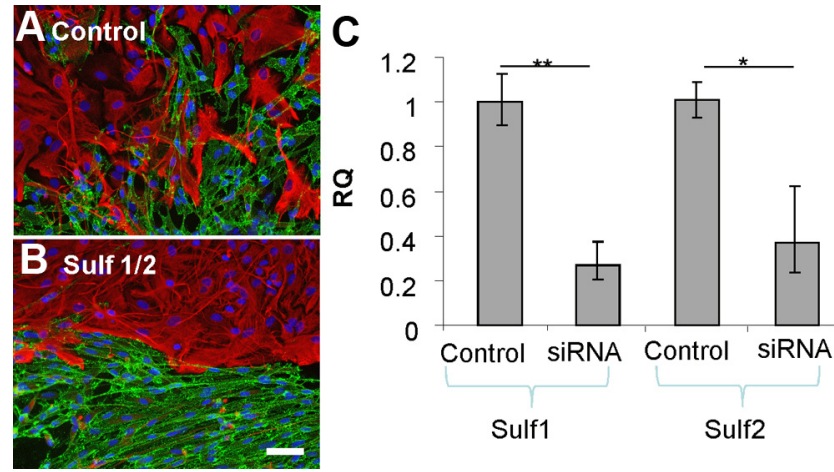

Figure 6. Knockdown of Sulf expression in OECs promotes boundary formation with astrocytes. $\boldsymbol{A}, \boldsymbol{B}$, Confrontation assays were performed using astrocytes and either $0 \mathrm{EC}$ transfected with nontargeting control siRNA $(\boldsymbol{A})$ or OECs transfected with siRNAs targeted to Sulf 1 and Sulf 2 (B). After $2 \mathrm{~d}$, cells were fixed and stained for GFAP (red) and $\mathrm{p} 75^{\mathrm{NTR}}$ (green). OEC s depleted of Sulf 1 and Sulf 2 expression formed a boundary on contact with astrocytes, whereas astrocytes and control-treated OECs mingled. $C$, The extent of gene knockdown was assessed by qPCR using RNA purified from siRNA-treated cells and from Sulf 1-specific and Sulf 2-specific primers and was found to be $\sim 70$ and $\sim 63 \%$ reduced respectively. Error bars indicate $\pm S E M$. Scale bar, $50 \mu \mathrm{m} .{ }^{*} p<0.05,{ }^{* *} p<0.01$ versus control.

formation (Fig. 2C,D,F), while combining the separately treated SCM samples reconstituted its biological activity and induced boundary formation (Fig. $2 E, F$ ). These data demonstrate that the activity of SCM in inducing boundary formation between cells requires both an HS and a protein component, and that individually these components are insufficient to induce a boundary.

\section{HS sulfation determines the induction of} OEC-astrocyte boundaries

To establish the effects of sulfation pattern on the inductive activity of HS, a panel of structurally defined, chemically modified (selectively desulfated) heparins were used to investigate the structural specificity of HS activity on boundary formation. After treatment with modified heparins $(10 \mu \mathrm{g} / \mathrm{ml}$ ) for $2 \mathrm{~d}$, confrontation assays were stained for $\mathrm{p} 75^{\mathrm{NTR}}$ and GFAP to visualize OECs and astrocytes, respectively. Results indicated that the most highly sulfated heparins [normal heparin (Hep 1) or oversulfated heparin (Hep 9)] induced the strongest boundaries between OECs and astrocytes (Fig. 3A,I), while lower sulfated heparin variants allowed OECs and astrocytes to mingle (Fig. $3 E-H$ ). Interestingly, boundary formation was particularly dependent on $\mathrm{O}$-sulfation, since $N$-acetylated heparin (in which $N$-sulfates are replaced with $N$-acetyl groups) induced significant boundary formation (Fig. 3B, Hep 2), whereas either de-2-Osulfated or de-6-O-sulfated heparins demonstrated lower boundary-forming activity (Fig. 3C,D, Hep 3 and 4).

\section{SCs secrete more highly sulfated HS than OECs}

Since we have shown that HS in SCM plays an active role in boundary formation, we directly analyzed the structure of HS synthesized by SCs and OECs and shed into their surrounding environment. The disaccharide composition of SCM and OCM HS was, therefore, analyzed via separation by SAX HPLC (Fig. 4A,B) and the relative abundance of each of the eight standard HS disaccharides were calculated as a percentage of total HS (Fig. 4C). SCM contains $\sim 2$-fold more HS than OCM and, in addition, SCM HS is more highly sulfated, with an average of 1.02 sulfates per disaccharide, compared with 0.75 sulfates per disaccharide in OCM HS (Fig. 4D). SCM HS consists of a higher proportion of disulfated and trisulfated disaccharides (disaccharides 4, 5, 8, and 6) compared with OCM HS, and also a higher proportion of the singly 6-O-sulfated disaccharide (disaccharide 2). OCM HS, in contrast, contains a higher proportion of the unsulfated disaccharide (disaccharide 1). The proportion of singly $\mathrm{N}$-sulfated (disaccharide 3 ) and singly 2-O-sulfated (disaccharide 7) disaccharides are similar in HS from both conditioned media.

\section{SCs and OECs express different levels of HS biosynthetic enzymes}

To determine whether differences in the expression of HS biosynthetic enzymes could account for the higher sulfation of SCM HS, quantitative PCR was performed using CDNA generated from monocultures of OECs and SCs. While there appeared to be a trend toward differences in expression of several enzymes by SCs compared with OECs, these were not significant due to variability in biological replicates. For example, there were no significant differences in the expression of $N$-deacetylase/ $N$-sulfotransferase (NDST1-4) enzymes or many of the sulfotransferase enzymes. However, HS 6-O-sulfotransferase 2 (HS6ST2) was expressed at a significantly higher level by OECs compared with SCs (Fig. 5B). In addition, HS 6-O-sulfotransferase 3 (HS6ST3) and HS 3-Osulfotransferase $3 \mathrm{a} 1$ (HS3ST3a1) were found to be uniquely expressed by OECs and HS 3-O-sulfotransferase 6 (HS3ST6) was 
uniquely expressed by SCs (Fig. 5A). Interestingly, OECs express significantly higher levels of HS 6-O-sulfatase enzymes compared with SCs (Sulf 1 and Sulf 2; 8-fold and 4-fold respectively) (Fig. 5C), which would be expected to reduce 6-O-sulfation of OEC HS. These differences in HS biosynthetic and modification enzymes provide a potential explanation for the structural differences in HS synthesized and secreted by the two glial cell types. SCs and OECs express similar levels of the most common HSPG core proteins (Fig. $5 D-E$ ).

\section{Reduction of Sulf 1 and Sulf 2 expression in OECs using RNAi promotes boundary formation with astrocytes}

Consistent with increased levels of 6-Osulfated HS in SCM, qPCR data indicated that SCs express lower levels of Sulf 1 and Sulf 2 6-O-endosulfatase enzymes compared with OECs. To determine whether this was important for the ability of SCs to induce a boundary with astrocytes, we transfected OECs with siRNA targeted to Sulf 1 and Sulf 2 to see whether the reduction in Sulf activity converted them to a more SC-like phenotype in confrontation assays. Before the addition of astrocytes, OECs were transfected with siRNA for $72 \mathrm{~h}$ and the reduction of Sulf 1 and Sulf $2 \mathrm{mRNA}$ was confirmed by qPCR $(\sim 73$ and $\sim 63 \%$ knockdown respectively). Once the cells had met in confrontation assays, the numbers of OECs mingling with astrocytes across a $300 \mu \mathrm{m}$ line were counted. Significantly fewer Sulf siRNA-treated OECs crossed into the astrocyte monolayer than control siRNA-treated OECs $(4.6 \pm 1.3$ Sulf siRNA cells compared with $15 \pm 1.8$ control SiRNA OECs. $p<0.01$ ) and a clear boundary was observed, whereas control OECs and astrocytes mingled freely (Fig. 6A,B). This suggests that an increase in HS 6-O-sulfation in OECs, via reduced Sulf expression, induces SClike behavior. The complimentary experiment to overexpress Sulf 1 and Sulf 2 in SCs to determine whether they adopted an OEClike phenotype was attempted using pcDNA3.1/Myc-His(-)MSulf-1 and pcDNA3.1/Myc-His(-)-MSulf-2 (Morimoto-Tomita et al., 2002). However, it was not possible to gain conclusive data using transfected cells in confrontation assays due to the low transfection efficiency of primary SCs $(<3 \%$, data not shown). This has also been reported by others (Kraus et al., 2010). We devised an alternative experiment based on the hypothesis that it may be possible to interfere competitively with endogenous highly sulfated HS in SC-astrocyte boundaries using an excess of low-sulfated modified heparins that do not promote boundary formation (Fig. 3, Hep 6, 7, and 8). Confrontation assays of SC and astrocytes treated with each of the low-sulfated modified heparins demonstrated significantly increased cell mingling (Fig. 7), confirming our hypothesis that these HS mimetics can inhibit boundary formation, presumably by competing for endogenous FGF ligands and reducing activation of astrocyte FGF receptors.
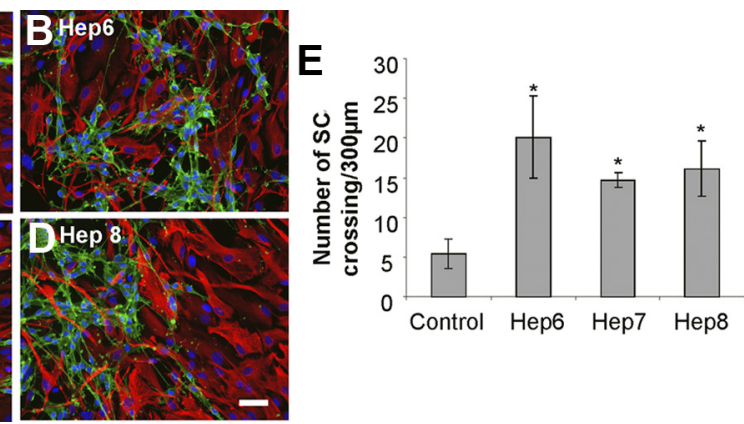

Figure 7. Interference of endogenous $\mathrm{SC} H S$ function using $\mathrm{HS}$ mimetics to inhibit boundary formation. $A-D$, Confrontation of $S$ S and astrocytes were performed in the absence $(\boldsymbol{A})$ or presence $(\boldsymbol{B}-\boldsymbol{D})$ of $10 \mu \mathrm{g} / \mathrm{ml}$ of selectively chemically modified heparins (Hep 6, 7, and 8; Fig. 3, structural details) with low levels of sulfation. $\boldsymbol{E}$, After 2 d of treatment, cells were fixed and stained for GFAP (red) and p75 ${ }^{\text {NTR }}$ (green) and the numbers of SCs mingling with astrocytes across a $300 \mu \mathrm{m}$ line were counted. The addition of low-sulfated modified heparins ( $\mathrm{HS}$ mimetics) to confrontation assays resulted in an increased number of $\mathrm{SC}$ s mingling with astrocytes $(\boldsymbol{B}-\boldsymbol{D})$ compared with control cultures $(\boldsymbol{A})$. Error bars indicate \pm SEM. Scale bar, $50 \mu \mathrm{m}$. ${ }^{*} p<0.05$ versus control.
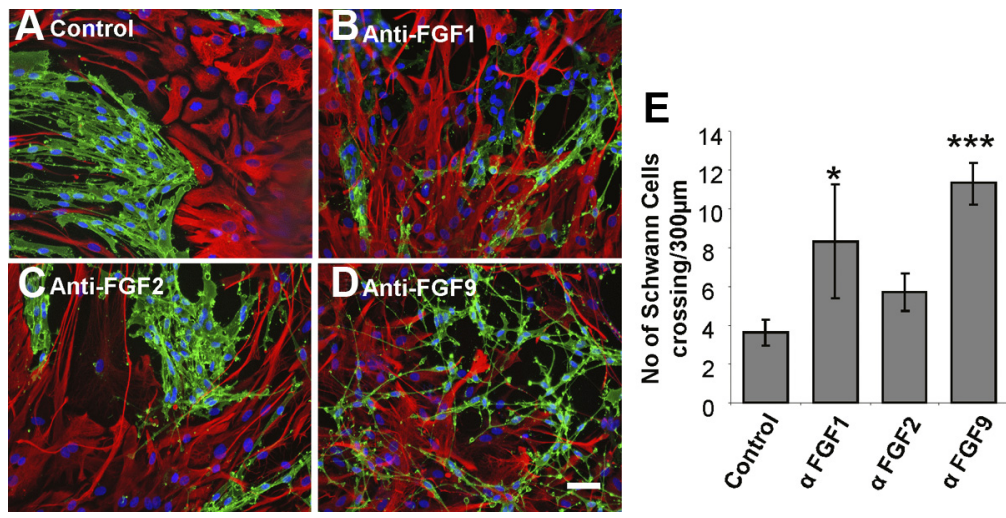

Figure 8. Neutralization of FGF1 and FGF9 disrupts boundary formation between SCs and astrocytes. SC and astrocyte confrontation assays (control boundary formation, $\boldsymbol{A}$ ) were treated with $1 \mu \mathrm{g} / \mathrm{ml} \mathrm{FGF1-blocking} \mathrm{antibodies} \mathrm{(B),} \mathrm{FGF2-blocking} \mathrm{antibodies}$ (C), or FGF9-blocking antibodies (D) for $2 \mathrm{~d}$ after the cell populations had met. $\boldsymbol{E}$, Cells were fixed and stained for GFAP (red) and (green) and the numbers of SCs mingling with astrocytes across a $300 \mu \mathrm{m}$ line were counted $(\boldsymbol{E})$. Neutralization of FGF1 and GF9, but not FGF2, resulted in an increase in mingling between $\mathrm{SC}$ and astrocytes compared with control cultures $(\boldsymbol{A})$. Error bars indicate \pm SEM. Scale bar, $50 \mu \mathrm{m} .{ }^{*} p<0.05,{ }^{* * *} p<0.001$ versus control.

\section{Inhibition of FGF1 or FGF9 disrupts SC boundary formation} with astrocytes

It has long been established that HS is required for the proper function of FGF by supporting the binding of all members of the FGF family to their cognate FGF receptors (Rapraeger et al., 1991; Yayon et al., 1991; Ornitz et al., 1992). The differential sulfation of HS is also known to regulate FGF activity (Guimond et al., 1993; Pye et al., 1998). Previously, it has been shown that FGF receptor inhibition disrupts SCM-induced boundary formation in OEC-astrocyte cultures (Santos-Silva et al., 2007), suggesting that a target of HS regulation of boundary formation is a member of the FGF family. We, therefore, investigated the role of particular FGF ligands in boundary formation. The FGF receptor inhibitor used in the aforementioned study (SU5402) was previously thought to specifically inhibit FGF receptor 1 . However, it has also been shown to effectively inhibit FGF receptor 3 (Grand et al., 2004; Paterson et al., 2004). Astrocytes, but not OECs or SCs, express FGF receptor 3-IIIb (Santos-Silva et al., 2007), suggesting that the response observed with the SU5402 inhibitor in confrontation assays may be due to inhibition of this receptor on astrocytes. FGF1 and FGF9 are the only known ligands for FGF receptor 3-IIIb (Chellaiah et al., 1994; Hecht et al., 1995; Santos-Ocampo et al., 1996). Therefore, the effect of block- 


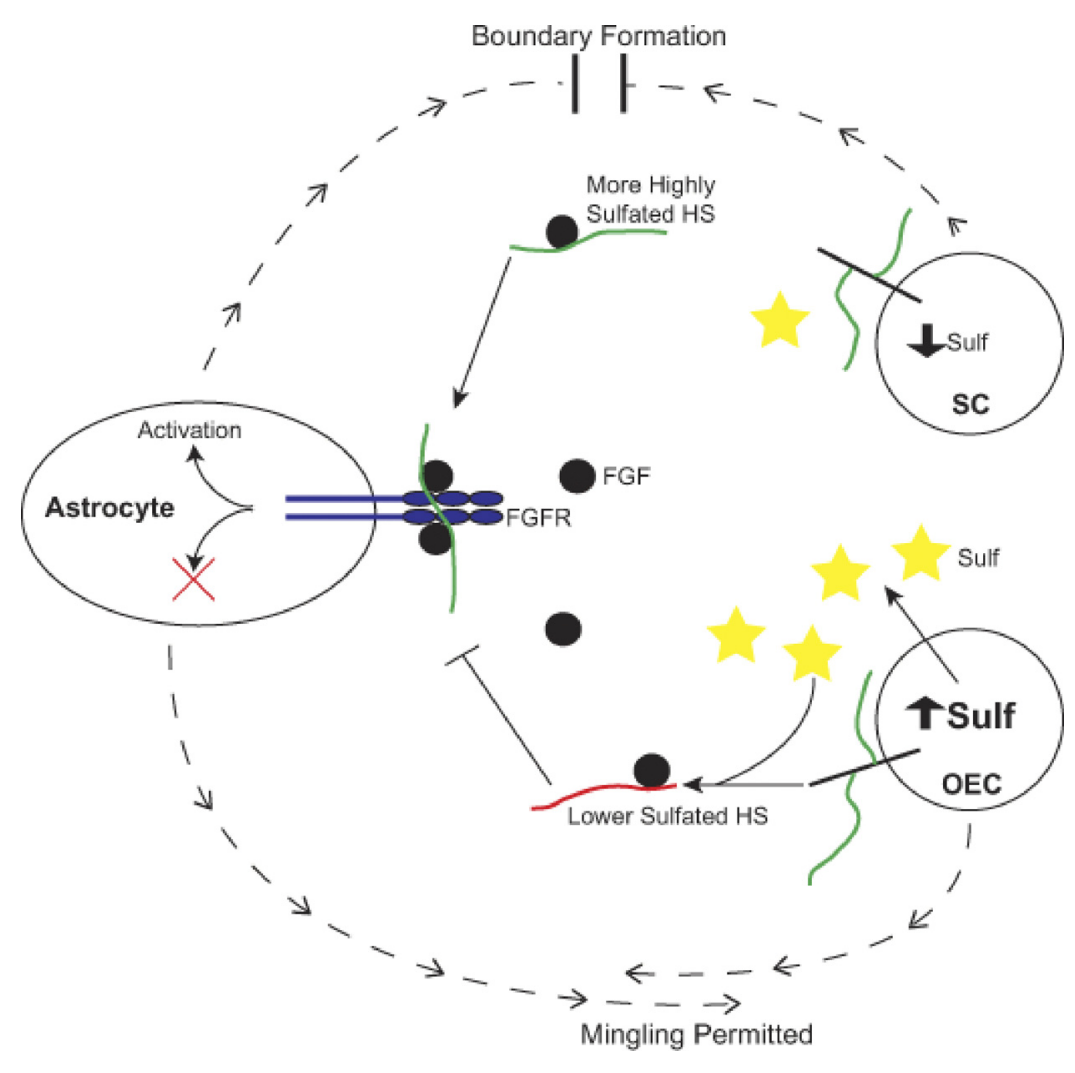

Figure 9. Model of HS function in SC-astrocyte boundary formation. SC s secrete a highly sulfated HS (green chains) because of low-level expression of Sulf enzymes. This HS promotes FGF1 and/or FGF9 ligand (black circles) binding to and/or activation of FGF receptor 3-Illb (blue) on astrocytes, activating intracellular signaling pathways and resulting in altered cell phenotype (blocking of mingling) and the formation of a boundary. OECS secrete a lower sulfated HS (red chains) because of higher expression of Sulf enzymes (yellow stars), which selectively remove 6-0-sulfates. These lower sulfated HS chains cannot promote FGF1 or FGF9 binding to and/or activation of FGF receptor 3-IIIb (FGFR) on astrocytes, and so fail to activate the required signaling pathways that lead to boundary formation, thus enabling $\mathrm{OECS}$ to mingle with astrocytes.

ing FGF1 or FGF9 using neutralizing antibodies was investigated. Since FGF receptor 3-IIIb does not bind FGF2 (Chellaiah et al., 1994), a neutralizing antibody against FGF2 was used as a negative control. Inhibition of FGF1 or FGF9 in SC-astrocyte confrontation assays resulted in reduced boundary formation and increased cell mingling, whereas inhibition of FGF2 had no effect (Fig. 8).

\section{Discussion}

Glial cell transplantation is a promising strategy for the repair of damaged CNS following injury or disease, with OECs and SCs as potential candidates. OECs may be the preferred candidate due to their ability to evoke less of a stress response in astrocytes (Lakatos et al., 2000; Fairless and Barnett, 2005; Santos-Silva et al., 2007). However, SCs often invade the CNS after injury when the blood-brain barrier is breached (Bruce et al., 2000), triggering an astrocytic stress response. The mechanisms by which SCs induce this response must be understood so that strategies can be devised to prevent it. Previously, it has been shown that addition of heparin to OEC-astrocyte cocultures induces boundary formation and removal of endogenous HS or inhibition of HS sulfation in SC-astrocyte cultures results in cell mingling (SantosSilva et al., 2007). In this study, we have demonstrated that the sulfation of HS synthesized by SCs and OECs is a crucial feature of their molecular phenotype influencing their activity on contacting astrocytes. The ability of HS to induce a boundary between SCs and astrocytes is shown to be dependent upon the level and pattern of HS sulfation, is modulated by the extracellular sulfatases Sulf 1 and Sulf 2 , and is likely to be mediated via FGF1 and/or FGF9 activation of astrocyte FGF receptor 3-IIIb signaling. This information provides new targets for the development of strategies to enhance posttransplantation integration of SCs into CNS tissue.

Using chemically modified heparins, which are model HS compounds with different levels of sulfation, it was possible to correlate HS sulfation with the extent of mingling-boundary formation induced in OEC-astrocyte confrontation assays. The more highly sulfated structures induced a stronger OEC-astrocyte boundary compared with the less sulfated structures, with a particular dependence on $\mathrm{O}$-sulfation (Fig. 3). In support of this, HS isolated from SCM, which induces a boundary in OEC-astrocyte cultures, was $27 \%$ more sulfated than OCM HS, with a particular enhancement of 6-Osulfated and 2-O-sulfated disaccharides (Fig. 4). Differences in the structure of HS synthesized by the glial cells will reflect a difference in biological activity and function, since HS-protein interactions are mediated by specific HS structures. For example, FGF family members show variations in the optimal HS sugar motifs required for binding. Consider FGF1 and FGF2. FGF1 has been shown to bind IdoA(2S)-GlcNS-containing oligosaccharides that are additionally 6 - $O$-sulfated, whereas binding of FGF2 to HS does not appear to require 6-O-sulfation (Turnbull et al., 1992; Maccarana et al., 1993; Kreuger et al., 1999, 2001; Ashikari-Hada et al., 2004). However, 6-O-sulfated HS is necessary for FGF2-dependent signaling, suggesting that, although not required for the initial FGF-HS interaction, 6-O-sulfated HS structures participate in HS-FGF-FGF receptor interactions and the formation of active signaling complexes (Guimond et al., 1993; Pye et al., 1998). The requirement of distinct HS structures for protein binding and variations in HS-protein binding kinetics (Powell et al., 2002) has been suggested to influence the assembly of particular ternary complexes and their frequency of formation (e.g., specific FGFFGF receptor pairs), thus regulating growth factor signaling dynamics (Kan et al., 1999; Powell et al., 2002; Allen and Rapraeger, 2003). Variations in the fine structure of HS synthesized by SCs and OECs are, therefore, anticipated to result in differences in biological activity via altered interactions with protein-binding partners, such as FGFs (Fig. 9).

To investigate possible mechanisms underlying the differences in HS structure synthesized by SCs and OECs, the expression of HS biosynthetic enzymes by the two glial cell types were analyzed. The majority of enzymes were expressed at comparable levels by SCs and OECs, although some differences were observed, with OECs expressing a number of sulfotransferase enzymes at a higher level than SCs (Fig. 5). However, it is noteworthy that enzyme mRNA levels do not necessarily directly reflect the resulting HS structure that is synthesized and the 
mechanisms regulating the HS biosynthetic machinery remain incompletely understood. Furthermore, a number of HS biosynthetic enzymes may be chiefly regulated at the translational level through the presence of structured $5^{\prime}$-untranslated regions and internal ribosomal entry sites, allowing cells to regulate the level of translation, which is particularly relevant for regulatory proteins (Grobe and Esko, 2002). In addition, HS biosynthetic enzymes have been shown to interact and form complexes, further regulating their activities in vivo (Esko and Selleck, 2002; Presto et al., 2008).

Of more direct interest, HS 6-O-sulfatase enzymes Sulf 1 and Sulf 2 were found to be expressed at lower levels by SCs compared with OECs (Fig. 5). To selectively remove 6-O-sulfates and "finetune" the final HS structure, these enzymes act extracellularly on sulfated HS chains postsynthesis (Dhoot et al., 2001; MorimotoTomita et al., 2002; Ai et al., 2006). Lower expression of Sulfs by SCs is, therefore, anticipated to result in changes to 6-O-sulfation in the mature HS chains synthesized, which was confirmed by our HPLC data. Differences in other sulfate moieties were also observed in our HPLC disaccharide analysis (e.g., the 2-O-sulfated/ 6-O-sulfated disaccharide). These differences can also be attributed to distinct levels of Sulf expression, since feedback mechanisms have been identified between Sulfs and other members of HS biosynthetic machinery, such that Sulf expression levels influence not only 6-O-sulfation, but also, to some extent, $\mathrm{N}$-sulfation and 2-O-sulfation (Lamanna et al., 2008).

Further evidence for a role of Sulf-modified HS in boundary formation was obtained by siRNA-mediated knockdown of Sulf 1 and Sulf 2 expression in OECs (Fig. 6). Cell behavior was altered dramatically, resulting in a phenotypic switch toward a SC-like response on contact with astrocytes and formation of a boundary. This strongly suggests that Sulf enzymes expressed by OECs play a vital role in modifying $\mathrm{HS}$ fine structure to determine their biological function. Removal of specific 6-O-sulfates from $\mathrm{HS}$ by Sulf enzymes will affect HS-protein interactions and, therefore, subsequent signaling pathways involved in boundary formation, allowing the cells to mingle with astrocytes. Reduction in Sulf enzyme expression diminishes this extracellular control of HS 6-O-sulfation, resulting in the synthesis of OEC HS that is more highly sulfated and SC-like and, thus, able to activate the signaling cascades that underlie boundary formation. Conversely, by saturating SC-astrocyte confrontation assays with low-sulfated HS mimetics, we demonstrated that it is possible to inhibit SC-induced boundary formation (Fig. 7), potentially by outcompeting SC HS for the activating FGF ligands. This is consistent with the notion that highly sulfated HS produced by SCs is essential for activation of boundary-forming signaling pathways.

In addition to the requirement for an HS component in SCM to induce an OEC-astrocyte boundary, a protein factor in SCM is also needed, since treatment of SCM with trypsin abolishes SCM activity. Reconstitution of separately heparinase-treated or trypsin-treated SCM samples restores SCM activity, further demonstrating the necessity of both an HS and protein component for activity (Fig. 2). In our previous work, FGFs were implicated, since inhibition of FGF receptor in SC-astrocyte cultures and OEC-astrocyte cultures treated with SCM reduced astrocyte hypertrophy and boundary formation (Santos-Silva et al., 2007). Notably, in the same study, the expression of FGF receptors in SCs, OECs, and cortical astrocytes were analyzed, and FGF receptor 3-IIIb was found to be uniquely expressed by astrocytes. FGF1 and FGF9 are the only known ligands for FGF receptor 3-IIIb (Chellaiah et al., 1994; Hecht et al., 1995; Santos-Ocampo et al.,
1996). In the current study, inhibition of FGF1 and FGF9 activity in confrontation assays resulted in mingling of SCs and astrocytes, while inhibition of FGF2 had no effect (Fig. 8). Interestingly, FGF9, also known as glial activating factor (Santos-Ocampo et al., 1996), has previously been reported to stimulate GFAP expression in human glioma cells (Miyagi et al., 1999), a process that also occurs during boundary formation (Lakatos et al., 2000). These data are consistent with the notion that signaling through FGF receptor 3 -IIIb is crucial for astrocyte boundary formation.

Figure 9 presents a model in which FGF1 and/or FGF9 can only bind to and activate FGF receptor 3-IIIb if a more highly sulfated HS is present in the conditioned medium via direct secretion of an extracellular matrix HSPG, such as perlecan, or by shedding of cell surface HSPGs, such as syndecans (Asundi et al., 2003; Ramani et al., 2012) or glypicans (Kreuger et al., 2004; Traister et al., 2008). This leads to activation of astrocytes and subsequent boundary formation with SCs. Lower sulfated HS synthesized by OECs, formed as a result of higher Sulf expression, cannot support FGF-induced FGF receptor 3-IIIb signaling, resulting in mingling between astrocytes and OECs. However, it cannot be discounted that FGF receptor 1, which is expressed by all three glial cell types, may be differentially activated and may also play a role in boundary formation.

It has been demonstrated in previous work that $\mathrm{N}$-cadherin influences boundary formation and differentially regulates SC and OEC adhesion and migration responses upon contact with astrocytes (Fairless et al., 2005). The N-cadherin-dependent pathway involved in astrocytosis and boundary formation may be independent of the FGF/HS-dependent pathway or, alternatively, the two may be cooperatively linked, since interactions between FGF receptors and N-cadherins have been demonstrated (Utton et al., 2001; Williams et al., 2001; Suyama et al., 2002; Sanchez-Heras et al., 2006). Other reports have demonstrated a role for ephrins in SC-astrocyte boundary formation, since blocking the EphA receptors reduces boundary formation (Afshari et al., 2010a). While there may not be a direct link between HS/FGF and ephrin signaling, they may be working in combination to induce a boundary following cell-cell contact. A function for chondroitin sulfate proteoglycans (CSPGs) in SC migration on astrocytes has also been demonstrated via modulation of integrin function (Afshari et al., 2010b). However, the evidence gained in the present study suggests that HSPGs function via a separate mechanism to CSPGs.

The findings of this study afford the prospect for significant advancements in combinatorial approaches for CNS repair after injury and in neurodegenerative diseases in which astrocytes become reactive. For example, a novel strategy could be to transiently modify HS structure by modulating the expression of HS sulfatase enzymes in transplanted SCs to enhance engraftment. It may also be possible to manipulate HS sulfation levels at the CNS injury site, possibly by direct addition of Sulf enzymes into the lesion, or alternatively, to interfere with endogenous HS activities using HS mimetics. Further work is necessary to determine the validity of these approaches as novel strategies for CNS repair.

\section{References}

Afshari FT, Kwok JC, Fawcett JW (2010a) Astrocyte-produced ephrins inhibit schwann cell migration via VAV2 signaling. J Neurosci 30:42464255 .

Afshari FT, Kwok JC, White L, Fawcett JW (2010b) Schwann cell migration is integrin-dependent and inhibited by astrocyte-produced aggrecan. Glia 58:857-869.

Ai X, Do AT, Kusche-Gullberg M, Lindahl U, Lu K, Emerson CP Jr (2006) 
Substrate specificity and domain functions of extracellular heparan sulfate 6-O-endosulfatases, QSulf1 and QSulf2. J Biol Chem 281:4969-4976.

Alexander CL, Fitzgerald UF, Barnett SC (2002) Identification of growth factors that promote long-term proliferation of olfactory ensheathing cells and modulate their antigenic phenotype. Glia 37:349-364.

Allen BL, Rapraeger AC (2003) Spatial and temporal expression of heparan sulfate in mouse development regulates FGF and FGF receptor assembly. J Cell Biol 163:637-648.

Ashikari-Hada S, Habuchi H, Kariya Y, Itoh N, Reddi AH, Kimata K (2004) Characterization of growth factor-binding structures in heparin/heparan sulfate using an octasaccharide library. J Biol Chem 279:12346-12354.

Asundi VK, Erdman R, Stahl RC, Carey DJ (2003) Matrix metalloproteinasedependent shedding of syndecan-3, a transmembrane heparan sulfate proteoglycan, in Schwann cells. J Neurosci Res 73:593-602.

Barnett SC, Riddell JS (2007) Olfactory ensheathing cell transplantation as a strategy for spinal cord repair-what can it achieve? Nat Clin Pract Neurol 3:152-161.

Bottenstein J, Hayashi I, Hutchings S, Masui H, Mather J, McClure DB, Ohasa S, Rizzino A, Sato G, Serrero G, Wolfe R, Wu R (1979) The growth of cells in serum free hormone supplemented media. Methods Enzymol 58:94-109.

Brickman YG, Ford MD, Gallagher JT, Nurcombe V, Bartlett PF, Turnbull JE (1998) Structural modification of fibroblast growth factor-binding heparan sulfate at a determinative stage of neural development. J Biol Chem 273:4350-4359.

Brockes JP, Fields KL, Raff MC (1979) Studies on cultured rat Schwann cells. I. Establishment of purified populations from cultures of peripheral nerve. Brain Res 165:105-118.

Bruce JH, Norenberg MD, Kraydieh S, Puckett W, Marcillo A, Dietrich D (2000) Schwannosis: role of gliosis and proteoglycan in human spinal cord injury. J Neurotrauma 17:781-788.

Chellaiah AT, McEwen DG, Werner S, Xu J, Ornitz DM (1994) Fibroblast growth factor receptor (FGFR) 3. Alternative splicing in Ig-like domain III creates a receptor highly-specific for acidic FGF/FGF-1. J Biol Chem 269:11620-11627.

Chuah MI, West AK (2002) Cellular and molecular biology of ensheathing cells. Microsc Res Tech 58:216-227.

Dhoot GK, Gustafsson MK, Ai X, Sun W, Standiford DM, Emerson CP Jr (2001) Regulation of Wnt signaling and embryo patterning by an extracellular sulfatase. Science 293:1663-1666.

Esko JD (2001) Special considerations for proteoglycans and glycosaminoglycans and their purification. Curr Protoc Mol Biol Chapter 17: Unit17.12.

Esko JD, Selleck SB (2002) Order out of chaos: assembly of ligand binding sites in heparan sulfate. Annu Rev Biochem 71:435-471.

Fairless R, Barnett SC (2005) Olfactory ensheathing cells: their role in central nervous system repair. Int J Biochem Cell Biol 37:693-699.

Fairless R, Frame MC, Barnett SC (2005) N-cadherin differentially determines Schwann cell and olfactory ensheathing cell adhesion and migration responses upon contact with astrocytes. Mol Cell Neurosci 28:253-263.

Fawcett JW, Asher RA (1999) The glial scar and central nervous system repair. Brain Res Bull 49:377-391.

Ford-Perriss M, Guimond SE, Greferath U, Kita M, Grobe K, Habuchi H, Kimata K, Esko JD, Murphy M, Turnbull JE (2002) Variant heparan sulfates synthesized in developing mouse brain differentially regulate FGF signaling. Glycobiology 12:721-727.

Franklin RJ, Barnett SC (2000) Olfactory ensheathing cells and CNS regeneration: the sweet smell of success? Neuron 28:15-18.

Franssen EH, de Bree FM, Verhaagen J (2007) Olfactory ensheathing glia: their contribution to primary olfactory nervous system regeneration and their regenerative potential following transplantation into the injured spinal cord. Brain Res Rev 56:236-258.

Grand EK, Chase AJ, Heath C, Rahemtulla A, Cross NC (2004) Targeting FGFR3 in multiple myeloma: inhibition of $\mathrm{t}(4 ; 14)$-positive cells by SU5402 and PD173074. Leukemia 18:962-966.

Grobe K, Esko JD (2002) Regulated translation of heparan sulfate $\mathrm{N}$-acetylglucosamine $\mathrm{N}$-deacetylase/n-sulfotransferase isozymes by structured $5^{\prime}$-untranslated regions and internal ribosome entry sites. J Biol Chem 277:30699-30706.

Guimond SE, Turnbull JE (1999) Fibroblast growth factor receptor signalling is dictated by-specific heparan sulphate saccharides. Curr Biol 9:1343-1346.
Guimond SE, Turnbull JE, Yates EA (2006) Engineered bio-active polysaccharides from heparin. Macromol Biosci 6:681-686.

Guimond S, Maccarana M, Olwin BB, Lindahl U, Rapraeger AC (1993) Activating and inhibitory heparin sequences for FGF-2 (basic FGF). Distinct requirements for FGF-1, FGF-2, and FGF-4. J Biol Chem 268:23906-23914.

Hecht D, Zimmerman N, Bedford M, Avivi A, Yayon A (1995) Identification of fibroblast growth factor 9 (FGF9) as a high affinity, heparin dependent ligand for FGF receptors 3 and 2 but not for FGF receptors 1 and 4. Growth Factors 12:223-233.

Higginson JR, Barnett SC (2011) The culture of olfactory ensheathing cells (OECs)—a distinct glial cell type. Exp Neurol 229:2-9.

Irie A, Yates EA, Turnbull JE, Holt CE (2002) Specific heparan sulfate structures involved in retinal axon targeting. Development 129:61-70.

Kan M, Wu X, Wang F, McKeehan WL (1999) Specificity for fibroblast growth factors determined by heparan sulfate in a binary complex with the receptor kinase. J Biol Chem 274:15947-15952.

Kraus A, Tager J, Kohler K, Haerle M, Werden F, Schaller HE, Sinis N (2010) Non-viral genetic transfection of rat Schwann cells with FuGENE HD(c) lipofection and $\operatorname{AMAXA}(\mathrm{c})$ nucleofection is feasible but impairs cell viability. Neuron Glia Biol 6:225-230.

Kreuger J, Prydz K, Pettersson RF, Lindahl U, Salmivirta M (1999) Characterization of fibroblast growth factor 1 binding heparan sulfate domain. Glycobiology 9:723-729.

Kreuger J, Salmivirta M, Sturiale L, Giménez-Gallego G, Lindahl U (2001) Sequence analysis of heparan sulfate epitopes with graded affinities for fibroblast growth factors 1 and 2. J Biol Chem 276:30744-30752.

Kreuger J, Perez L, Giraldez AJ, Cohen SM (2004) Opposing activities of Dally-like glypican at high and low levels of Wingless morphogen activity. Dev Cell 7:503-512.

Lakatos A, Franklin RJ, Barnett SC (2000) Olfactory ensheathing cells and Schwann cells differ in their in vitro interactions with astrocytes. Glia 32:214-225.

Lakatos A, Barnett SC, Franklin RJ (2003) Olfactory ensheathing cells induce less host astrocyte response and chondroitin sulphate proteoglycan expression than Schwann cells following transplantation into adult CNS white matter. Exp Neurol 184:237-246.

Lamanna WC, Frese MA, Balleininger M, Dierks T (2008) Sulf loss influences $\mathrm{N}-$, 2-O-, and 6-O-sulfation of multiple heparan sulfate proteoglycans and modulates fibroblast growth factor signaling. J Biol Chem 283: 27724-27735.

Li Y, Field PM, Raisman G (2005) Olfactory ensheathing cells and olfactory nerve fibroblasts maintain continuous open channels for regrowth of olfactory nerve fibres. Glia 52:245-251.

Lyon M, Gallagher JT (1991) Purification and partial characterization of the major cell-associated heparan sulphate proteoglycan of rat liver. Biochem J 273:415-422.

Maccarana M, Casu B, Lindahl U (1993) Minimal sequence in heparin/ heparan sulfate required for binding of basic fibroblast growth factor. J Biol Chem 268:23898-23905.

Miyagi N, Kato S, Terasaki M, Aoki T, Sugita Y, Yamaguchi M, Shigemori M, Morimatsu M (1999) Fibroblast growth factor-9 (glia-activating factor) stimulates proliferation and production of glial fibrillary acidic protein in human gliomas either in the presence or in the absence of the endogenous growth factor expression. Oncol Rep 6:87-92.

Morimoto-Tomita M, Uchimura K, Werb Z, Hemmerich S, Rosen SD (2002) Cloning and characterization of two extracellular heparindegrading endosulfatases in mice and humans. J Biol Chem 277:4917549185.

Noble M, Murray K (1984) Purified astrocytes promote the in vitro division of a bipotential glial progenitor cell. EMBO J 3:2243-2247.

Ori A, Wilkinson MC, Fernig DG (2008) The heparanome and regulation of cell function: structures, functions and challenges. Front Biosci 13:43094338.

Ornitz DM, Yayon A, Flanagan JG, Svahn CM, Levi E, Leder P (1992) Heparin is required for cell-free binding of basic fibroblast growth factor to a soluble receptor and for mitogenesis in whole cells. Mol Cell Biol 12:240 247.

Paterson JL, Li Z, Wen XY, Masih-Khan E, Chang H, Pollett JB, Trudel S, Stewart AK (2004) Preclinical studies of fibroblast growth factor receptor 3 as a therapeutic target in multiple myeloma. Br J Haematol 124:595603. 
Patey SJ, Edwards EA, Yates EA, Turnbull JE (2006) Heparin derivatives as inhibitors of BACE-1, the Alzheimer's beta-secretase, with reduced activity against factor Xa and other proteases. J Med Chem 49:6129-6132.

Pekny M, Nilsson M (2005) Astrocyte activation and reactive gliosis. Glia 50:427-434.

Powell AK, Fernig DG, Turnbull JE (2002) Fibroblast growth factor receptors 1 and 2 interact differently with heparin/heparan sulfate. Implications for dynamic assembly of a ternary signaling complex. J Biol Chem 277:28554-28563.

Presto J, Thuveson M, Carlsson P, Busse M, Wilén M, Eriksson I, KuscheGullberg M, Kjellén L (2008) Heparan sulfate biosynthesis enzymes EXT1 and EXT2 affect NDST1 expression and heparan sulfate sulfation. Proc Natl Acad Sci U S A 105:4751-4756.

Pye DA, Vives RR, Turnbull JE, Hyde P, Gallagher JT (1998) Heparan sulfate oligosaccharides require 6-O-sulfation for promotion of basic fibroblast growth factor mitogenic activity. J Biol Chem 273:22936-22942.

Raisman G (1985) Specialized neuroglial arrangement may explain the capacity of vomeronasal axons to reinnervate central neurons. Neuroscience 14:237-254.

Raisman G (2001) Olfactory ensheathing cells_-another miracle cure for spinal cord injury? Nat Rev Neurosci 2:369-375.

Ramani VC, Pruett PS, Thompson CA, DeLucas LD, Sanderson RD (2012) Heparan sulfate chains of syndecan-1 regulate ectodomain shedding. J Biol Chem 287:9952-9961.

Rapraeger AC, Krufka A, Olwin BB (1991) Requirement of heparan sulfate for bFGF-mediated fibroblast growth and myoblast differentiation. Science 252:1705-1708.

Sanchez-Heras E, Howell FV, Williams G, Doherty P (2006) The fibroblast growth factor receptor acid box is essential for interactions with $\mathrm{N}$-cadherin and all of the major isoforms of neural cell adhesion molecule. J Biol Chem 281:35208-35216.

Santos-Ocampo S, Colvin JS, Chellaiah A, Ornitz DM (1996) Expression and biological activity of mouse fibroblast growth factor-9. J Biol Chem 271:1726-1731.

Santos-Silva A, Fairless R, Frame MC, Montague P, Smith GM, Toft A, Riddell JS, Barnett SC (2007) FGF/heparin differentially regulates Schwann cell and olfactory ensheathing cell interactions with astrocytes: a role in astrocytosis. J Neurosci 27:7154-7167.

Silver J, Miller JH (2004) Regeneration beyond the glial scar. Nat Rev Neurosci 5:146-156.

Skidmore M, Atrih A, Yates E, Turnbull JE (2009) Labelling heparan sul- phate saccharides with chromophore, fluorescence and mass tags for HPLC and MS separations. Methods Mol Biol 534:157-169.

Skidmore MA, Guimond SE, Dumax-Vorzet AF, Atrih A, Yates EA, Turnbull JE (2006) High sensitivity separation and detection of heparan sulfate disaccharides. J Chromatogr A 1135:52-56.

Skidmore MA, Guimond SE, Dumax-Vorzet AF, Yates EA, Turnbull JE (2010) Disaccharide compositional analysis of heparan sulfate and heparin polysaccharides using UV or high-sensitivity fluorescence (BODIPY) detection. Nat Protoc 5:1983-1992.

Suyama K, Shapiro I, Guttman M, Hazan RB (2002) A signaling pathway leading to metastasis is controlled by $\mathrm{N}$-cadherin and the FGF receptor. Cancer Cell 2:301-314.

Traister A, Shi W, Filmus J (2008) Mammalian Notum induces the release of glypicans and other GPI-anchored proteins from the cell surface. Biochem J 410:503-511.

Turnbull JE, Fernig DG, Ke Y, Wilkinson MC, Gallagher JT (1992) Identification of the basic fibroblast growth factor binding sequence in fibroblast heparan sulfate. J Biol Chem 267:10337-10341.

Utton MA, Eickholt B, Howell FV, Wallis J, Doherty P (2001) Soluble $\mathrm{N}$-cadherin stimulates fibroblast growth factor receptor dependent neurite outgrowth and $\mathrm{N}$-cadherin and the fibroblast growth factor receptor co-cluster in cells. J Neurochem 76:1421-1430.

Wilby MJ, Muir EM, Fok-Seang J, Gour BJ, Blaschuk OW, Fawcett JW (1999) N-cadherin inhibits Schwann cell migration on astrocytes. Mol Cell Neurosci 14:66-84.

Williams EJ, Williams G, Howell FV, Skaper SD, Walsh FS, Doherty P (2001) Identification of an $\mathrm{N}$-cadherin motif that can interact with the fibroblast growth factor receptor and is required for axonal growth. J Biol Chem 276:43879-43886.

Yan Q, Johnson EM Jr (1988) An immunohistochemical study of the nerve growth factor receptor in developing rats. J Neurosci 8:3481-3498.

Yates EA, Santini F, Guerrini M, Naggi A, Torri G, Casu B (1996) $1 \mathrm{H}$ and 13C NMR spectral assignments of the major sequences of twelve systematically modified heparin derivatives. Carbohydr Res 294: $15-27$.

Yates EA, Guimond SE, Turnbull JE (2004) Highly diverse heparan sulfate analogue libraries: providing access to expanded areas of sequence space for bioactivity screening. J Med Chem 47:277-280.

Yayon A, Klagsbrun M, Esko JD, Leder P, Ornitz DM (1991) Cell surface, heparin-like molecules are required for binding of basic fibroblast growth factor to its high affinity receptor. Cell 64:841-848. 